\title{
SOCIAL REALITY IN THE CONTEXT OF SOCIAL MEDIA AND MOBILE TECHNOLOGIES
}

\author{
Katarzyna ZAWIERUCHA \\ Faculty of Command Management, War Studies University, Warsaw, Poland; k.zawierucha@akademia.mil.pl, \\ ORCID: 0000-0002-9439-5589
}

Purpose: The article focuses on defining the concept of mobile technology and social media and presenting the novum aspects most affecting the social reality. The aim of the article is to emphasize the importance of mobile technologies and the continuous development of information technology in terms of the importance of social media. As a result, the article presents opportunities and threats to the world resulting from the use of the described technologies and gives an opinion on the rapid development in this aspect.

Design/methodology/approach: The considerations and analysis made it possible to identify the causes of excessive use of mobile technologies and to present the most commonly used types of social media.

Findings: The article shows the essence of mobile technologies and the likely direction of development in this aspect. The article defines the social reality in the context of social media and analyzes the modern world determined by technologies. The information contained in the article shows the huge increase in the importance of mobile technologies at the expense of real life and shows the priority of general improvement of the quality of life in favor of addiction and manipulation.

Originality/value: The information contained in the article defines the concept of mobile technologies, social media and social reality, presents selected issues related to these aspects and indicates the direction of world development in the context of the issues described.

Keywords: social media, mobile technology, social reality.

Category of the paper: review publication.

\section{Introduction}

The continuous development of the modern world caused by the development of information technologies, mainly mobile technologies, affects the inevitable changes in the social reality. The changes taking place in recent years have contributed to the analysis of the aspects of the present world in the perspective of further technological changes. The factor 
supporting taking up the indicated subject was the topicality of the essence of mobile technologies and the presentation of opportunities and threats accompanying its use.

Changing social platforms and the emergence of new platforms are part of today's world. However, not only the changing technology, but also the growing awareness of consumers, their education and knowledge of some functions creates today's reality. Currently, the basic communication tool is the Internet, using mobile technologies, and monitoring the Internet and social media allows you to achieve many benefits, both in private and professional life.

The new technology makes it possible to acquire new customers, improve the image, help stay ahead of the competition and get to know customers and their opinions better. From the point of view of marketing, a very important element is also cooperation with influencers in order to reach recipients of given products or services. Social media has such a strong position that they are able to manipulate huge numbers of users, and the right products go to inluencers who have the right target group for the product. Social media and mobile technologies give the opportunity to develop, meet people, establish contacts or maintain those already established. They develop awareness, facilitate access to many amenities that today's world offers and often give the opportunity to earn easy money.

Unfortunately, mobile technologies are also a huge source of addiction. The use of mobile technologies stimulates certain expected behaviors, deprives of control over surfing the Internet, over making decisions and expressing emotions. Lack of control related to long-term spending of time in virtual space negatively affects human sleep, leads to a syndrome phantom vibration, e.g. while waiting for a message, or makes a person more susceptible to the influence of a mobile device. It also seems probable that people addicted to the Internet, and thus to social media, cease to be a self-thinking people and constantly identify with other people, the so-called crowd mentality. This makes the situation very advantageous from an entrepreneur's perspective, and many companies invest huge amounts of money to be included in someone's post, e.g. on Instagram, as it will make many people buy the product without prior analysis. Unfortunately, this is not a favorable situation for the Internet user.

It is also worth noting that huge amounts of data and information are delivered to the recipient only so that the human brain will not be able to process them all and recognize which information is real and which is not. Mobile technologies that manipulate human functioning also negatively affect concentration, and the use of technology while performing an activity causes distraction.

Huge interest in mobile technologies, and thus social media, is inevitable, and not using what technology offers more and more often leads to the inability to function in today's world. People function on the border between the real and the virtual world or completely transfer their lives to the unreal world. The loss of interpersonal relationships caused by the excessive use of technology leads to loneliness and inability to function without technology and the Internet. 
The main purpose of the article is to identify mobile technologies and social media, to present the most popular social networking sites and to analyze the opportunities and threats resulting from the use of what technologies offer. In order to achieve the goal of the article, mobile technologies, social media and social reality have been defined, the benefits of using technologies and the dangers of improper or excessive use of mobile technologies have been presented, the presents the essence of functioning of technologies and determined the influence of technology on the development of the world.

\section{The concept of mobile technologies}

Multimedia devices are increasingly interfering with society and have a strong impact in areas related to work, entertainment, science, communication and a number of other services provided every day. Thanks to mobile technology, users have the ability to access the Internet, and thus to any services that use connectivity and to communicate with other people. Currently, interpersonal communication very often takes place via video calls, SMS/MMS messages, e-mail or instant messaging. Purchasing products and services involves shopping online, without leaving your home, with delivery to a selected place, current viewing of prices, opinions, availability and other desired information, and financial management is online or mobile banking and online payments. Users' attachment to mobile devices, often equated with addiction, leads to changes taking place in the area of spending free time, and contributes to the creation of new functions in order to meet newly emerging needs.

The term mobility comes from Latin (mobile) and means the ability of an object to move or the ability to be moved, as well as the movement itself. The term mobile technology, in turn, is associated with all kinds of devices, from the simplest mobile phones to the most advanced and newest discoveries of information technology, used for the most common use. Mobile technologies make it possible to process, retrieve and send any data without the need to use a wired connection to the network (Gajek, 2013).

Therefore, mobile technology applies to all tools, devices or products that can be used on the move. Taking into account information technologies, mobility is permanently connected with wireless networks, where their continuous progress and permanent presence conditions the functioning of electronic devices dedicated to work while being connected to the Internet. Therefore, the concept of wireless in the context of the operation of mobile devices with Internet access can be treated interchangeably with the concept of mobility (Pawełoszek, Korek, 2009).

The mutual penetration of mobile telephony (mainly smartphones) with the Internet creates the so-called mobile space (m-space), which is an extension of the Internet space, which is considered to be virtual space, i.e. an artificial reality, created thanks to information technology. 
Virtual reality, thanks to its technical infrastructure, enables the achievement of the goals of enterprises, institutions and private persons (Wielki, 2012).

Mobility, i.e. the ability to move a given device and the ability to use it on the move, is currently a scalable feature of mobile devices compared to the parameters related to the visual characteristics of devices, e.g. size or weight. The mobility of the device also includes work ergonomics related to the device's usability, interaction and functionality, resistance to environmental or weather conditions, e.g. water resistance, functionality related to data transmission, or the security of data transmission.

Mobile technologies can be divided according to the demand and comfort of use (Naismith et al., 2004):

- portable (portable) and personal, i.e. mobile phones, smartphones, latopes, tablets and other digital devices with mobile Internet,

- stationary and generally accessible, e.g. projectors, interactive boards, devices and software for videoconferencing, stationary consoles, language laboratory equipment and others.

The popularity of browsing the Internet with the use of mobile devices is growing rapidly, and their functioning has a key impact on the development of countries. It is also important to believe that the expenses of all companies on mobile creations are much higher than those spent, e.g. on newspaper advertisements. As mentioned, the changes that mobile technologies bring, apart from social life, revolutionize the sphere of business. The dynamic development of wireless access to the network, thanks to the use of mobile devices, opens up new opportunities for entrepreneurs operating in various business sectors, as well as individual sellers. This mainly applies to mobile e-commerce (m-commerce). This specific type of trade has its basis in e-commerce, but it is an extension of it with the possibility of making purchases at any place and time, thanks to the mobile technology which owes its name. Undoubtedly, the changing patterns and rules of social behavior show the huge potential of wireless solutions.

The increasing importance of mobile devices, mainly smartphones, greater mobility of society, improvement of communication processes, and an increase in data transfer speed lead to the formation of a society that has constant access to data regardless of the place and time (Krzysztofek, 2006). A huge number of portals, websites or services means that you can find almost any information on a specific topic on the Internet. Thanks to mobile technology, it is possible at any time and in any space, wherever there is a range of mobile telephony.

The vision of a society that exists thanks to free access to data creates a new type of society, i.e. a mobile society, living in a global village, where globalization and information technology create a social reality that is created every day. A society surrounded by mobility, which more and more often communicates through interactive dialogue instead of traditional communication, creating the present and the future. 
The elements that distinguish the mobile society are (Turban et al., 2002):

- basing the transmission of information on portable devices that user can have with you all the time - mobility,

- basing the transmitted information on wireless channels; user can be available at any place and time - reachable,

- sending multimedia messages thanks to technologically advanced end devices multimedia,

- sending information based on multidimensional databases containing complete information about the addressee - individualisation,

- transferring a part of the sphere of everyday life into virtual reality with a strong emphasis on continuous access to it - virtualization.

It is worth noting that the more mobile the society becomes, it produces more and more information useful for analysis, which in turn influences the phenomenon of profiling technology users. Distributing knowledge contributes to the creation of global information resources concerning the life of society. Up-to-date information provided from mobile devices allows the shaping of current and future user behavior. The dynamics of growth in the start of services offered by mobile technologies is triumphant. This is mainly visible in the examples of mobile applications for ordering car transport services by associating passengers with drivers using the application where the passenger is located and the payment for the service takes place online, services used to search for communication connections, streaming services, or applications for ordering couriers delivering food to the indicated address.

Currently, mobile devices are the most important for many people because they provide access to information and entertainment wherever the user is, and the time spent using the Internet is constantly increasing. It is also worth noting that the main model of a mobile device is considered to be a smartphone, which combines the functions of a mobile phone and a laptop, in addition, it is very handy and useful. The appearance of smartphones has not changed much, but their software is constantly changing in order to constantly increase the comfort of users and limit the activity of other modern products. Currently, you can find virtually every functionality in smartphones, you only need to download a specialized application. Unfortunately, this is a great risk for the protection of personal data because the user's personal data is not deleted with the subsequent removal of the application.

Indeed, the universality of mobile technologies results from the features that characterize them (Lysik, Machura, 2014):

- portable nature of the devices, small size, lightness of the devices and relatively low price,

- intuitive and simple operation,

- transparency as well as easy and quick operation of the system and applications, 
- here and now - thanks to the constant connection to the Internet and current technologies, mobile devices are fast and convenient solutions that allow access to key information regardless of place and time,

- a wide range of applications, allowing to meet the sophisticated needs of users,

- convergence, i.e. the use of more useful functions in one device; the most popular smartphone among generally available mobile technology is not only a telephone, but also a music player, camera, alarm clock, notebook, assistant, calendar or e-mail client, and thanks to the possibility of connecting external modules, e.g. via bluetooth technology, or USB, an ordinary smartphone can become a projector, teleconference set, hands-free set, etc.,

- multimedia character - contemporary solutions affect more than one sense, which increases their attractiveness in the eyes of users.

Thanks to mobile technology solutions, modern society gains many amenities, but is also exposed to many barriers and dangers of use. There is no doubt that mobile devices are much more than just a form of communication these days. This technology is a tool supporting human life every day, constituting its integral part in every aspect of functioning. Mobile devices enable (in addition to the aforementioned communication) the performance of many activities related to movement, work, entertainment, shopping or consumption of goods and services. However, it is important to find a balance in a rapidly changing world and use mobile technologies wisely and only for the right purposes.

\section{Social media and effective marketing}

Social media is the fastest-growing communication tool on the Internet that connects very closely with mobile devices. Social media are a form of data transfer via websites or applications operating on the Internet in the form of communities created by users of specific websites (Polańska, 2011). Social media is therefore part of virtual media, and their concept was most likely born with the rise of the Internet. Independence, freedom, equality of rights and information character, with the simultaneous use of advanced solutions of information technology, makes it possible for every user of virtual space to exist and express their opinion. It is worth noting, however, that social media, as a component of this type of medium, affect emotional aspects.

The idea of participating in social networking sites, which are the most popular part of social media, is expressed in establishing or maintaining previously established ties with members of a group, e.g. fans of a person, brand, or people sharing common passions. Therefore, social networking sites constitute an online service which, in principle, allows you to present your 
own profile to selected users of the portal or all its users. In addition, these websites also allow you to create lists of friends, thus linking a given user with other people (Czubkowska, 2010).

The basic functions of social media include (Mroz, 2010):

- the possibility of presenting a specific person, organization or product through a profile containing data shared with the amount of information appropriate for the user,

- freedom of establishing contacts, exchanging information and maintaining relationships between members of given groups operating in the area of the relevant social network,

- the prospect of publishing, sharing, commenting or rating content shared or sent by other users,

- making it possible to observe and track the activity of members of a given website or social group.

A typical form of social media functioning today are the already mentioned social networks functioning in the best known version, but more and more often they also take the form of blogs, channels or forums oscillating around a specific topic, e.g. business, products and services, social games, travel, or enabling posting and sharing photos, videos and stories.

It should be noted that with the emergence of social networking sites, new opportunities for enterprises have also arisen, resulting from the increased recognition of certain brands, and thus the increase in sales of products and services on the Internet, in line with the principle that every company should be where it is currently potential or regular customers.

Unfortunately, no social media is permanent, but for marketing purposes it is worth paying attention to each media in order to achieve the intended results. There are a large number of social networks in social media that are used for mutual communication and for companies to communicate with their internal or external environment. Each of the websites has unique features that make each website use a specific group of people.

Currently, Facebook remains the most popular social networking site in the world, operating with the Polish language version since 2008. The next places are occupied by the very popular website YouTube, which allows free uploading and rating of original films or with appropriate copyright and approval for distribution, followed by WhatsApp, an application used as an instant messaging app, but more popular abroad (Figure 1). 


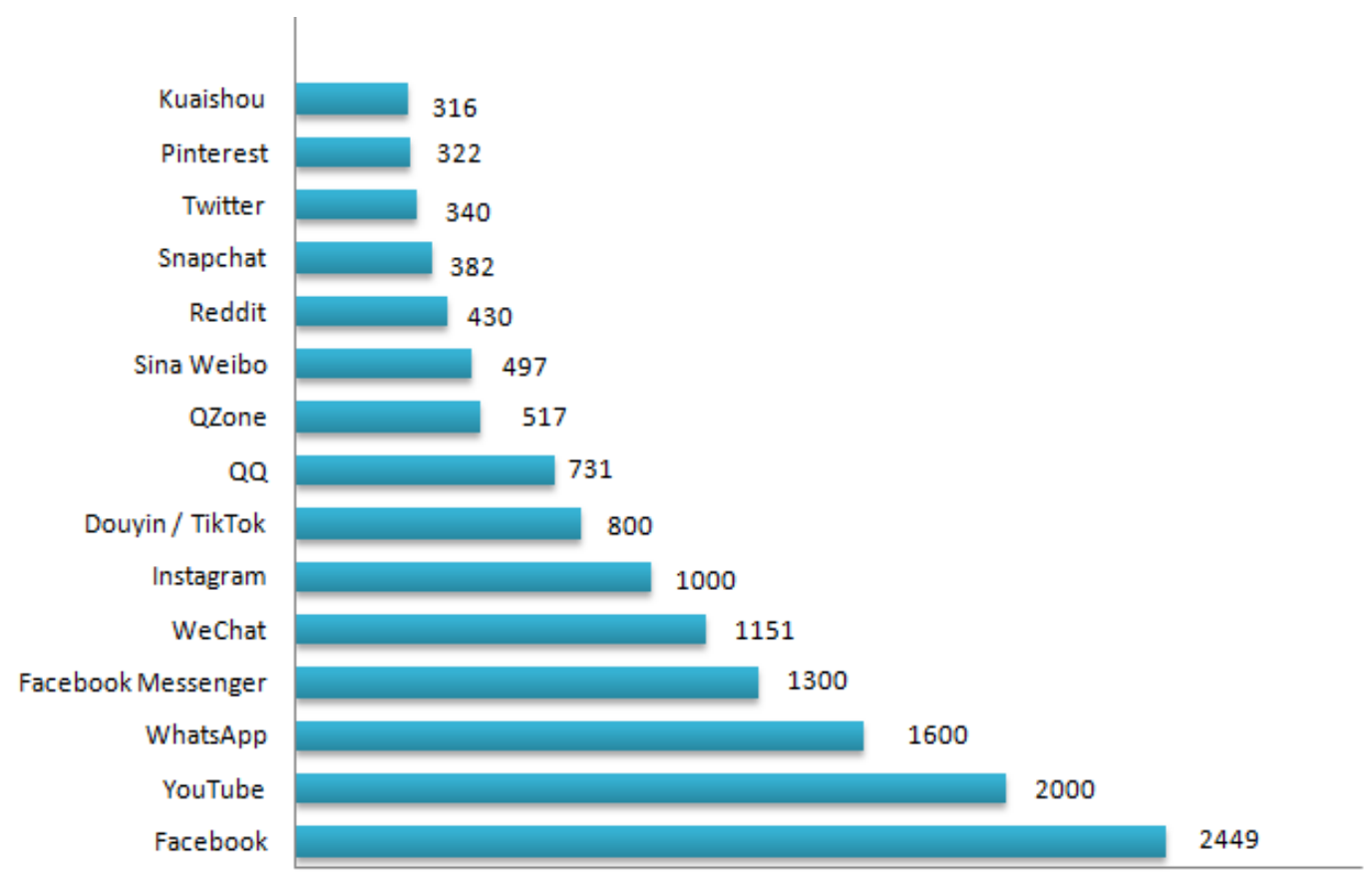

Figure 1. Most popular social networks wordwide in January 2020, ranked by number of active users (in milions). Source: prepared on the basis of https://socialpress.pl/2020/02/social-media-w-polsce-i-naswiecie-najnowsze-dane.

All kinds of applications, apart from individual forms of use, also serve as an advertisement or an opportunity to find out about the market. There are many companies registered on Facebook and other social networks that encourage people to buy a particular product or service. In addition, based on the likes of users, the portal sends website users content thematically similar to their interests, and based on activity, it is able to determine sexual preferences, political and religious views, evaluate property and locate the user, determine marital status, or even indicate the level of education.

The popularity of websites in Poland slightly differs from their frequency of use in comparison to the rest of the world (Figure 2). The most frequently chosen service in Poland is not Facebook, but YouTube. At the end of January 2020, 92\% of all Internet users used video service, facebook, which came in second place, by $89 \%$, and the messenger Messenger, which was created by Facebook by $72 \%$ of recipients. The differences between the popularity of some websites in Poland and in the world may be caused by the subsequent acquisition of users. 


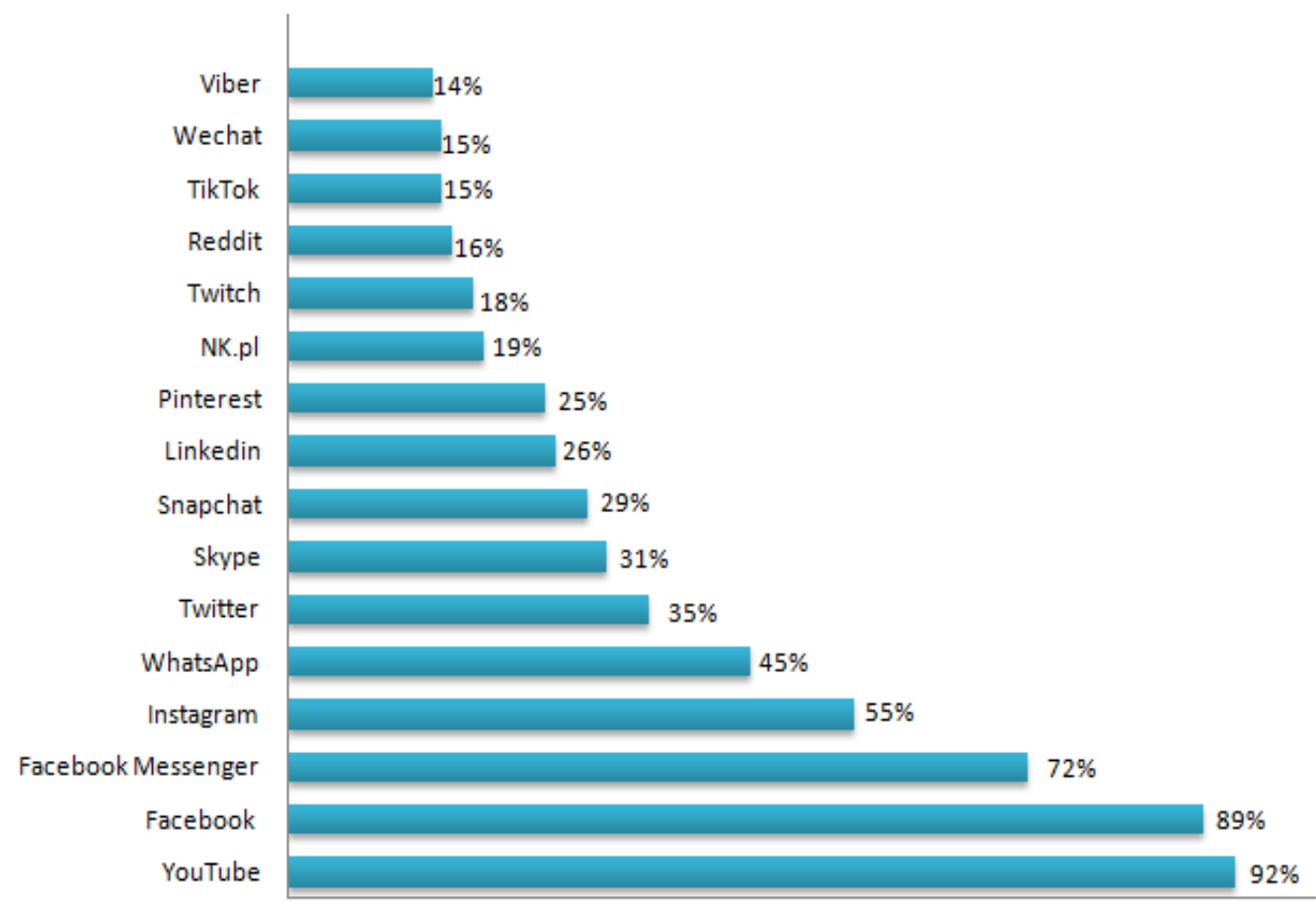

Figure 2. The most popular social media in Poland in January 2020, ranked by number of active users (in milions). Source: prepared on the basis of https://socialpress.pl/2020/02/social-media-w-polsce-i-naswiecie-najnowsze-dane.

As already mentioned, large enterprises very often use the help of famous people to encourage others to buy a given product or service, or to reach the awareness of new recipients. In turn, small and medium-sized enterprises can profit by encouraging micro influencers to cooperate. It is important to check which people with a large audience are able to influence the opinions and decisions of others, and which influencer has an engaged audience. In order to choose an influencer correctly, it is necessary to analyze the statistics concerning the growth of fans of a given influencer, i.e. purchase of fans and analysis of cooperation, which allows you to check whether the involvement of a given influencer actually allowed for the achievement of specific business goals. The awareness of asking a given influencer to cooperate is undoubtedly important from the point of view of the profits of a particular company. Unfortunately, from the point of view of the recipient, very often famous people, in order to sign new advertising contracts with brands, in order to increase their own wealth, use their position to encourage their fans to buy a product or service.

The market has changed a lot recently as a result of the development and growing popularity of social media. There are audiences who question the authenticity of Internet messages and advertisements and put pressure to choose products and services and trusted influencers more consciously. Unfortunately, there are also buyers of goods who are very naively led by online marketing.

Another way of advertising on the Internet is a strategy that encourages the recipients of given goods and services to share content related to the brand, e.g. photos, videos, location on their social profiles, marking a given brand or company or using a hashtag. The online world becomes a de facto second life for its users, and thus also becomes a place where sellers and 
buyers meet. Nowadays, society shares everything on social media, talks, shares insights, recommends brand data or advises against it. The mobile society pays attention to what their friends or idols are currently publishing, where they stand for and what products they use. Today, people are more likely to use products and services that have theoretically been tested by someone than those where their advantages are artificially presented. Additionally, some in order to feel like their idol use the same cosmetics, because they want to identify with this person, illusoryly be closer to her, increase their prestige or satisfy the curiosity of their own organism. Unfortunately, this is how effective but deceptive marketing is created. A user who says or shows a given product is a more authentic promotion for a given recipient than the seller. It is worth noting, however, that very often a person promoting a place, product or service does it only from the aforementioned material premises, in order to maintain popularity, following the current trend, or as a result of addiction to social media.

The rankings of the most popular and most followed web creators in Poland show a huge number of followers. Social media stars with the largest number of fans or subscribers are followed by multi-million audience groups. For Polish influencers, in addition to the total number of followers, popularity is also important in terms of the number of likes, shares, comments, or engagement taking into account the average value of interactions with a single post, as well as the number of visits in the blog. The most engaging influencers in Poland are the influential creators of YouTube, Instagram, TikToka and Blogs. The increased interest in people who influence the environment causes the desire to pursue a profession such as youtuber or social media influencer.

It should be noted that the good impact of such activities can be justified by promoting regular research, encouraging voting, proper nutrition, reducing waste production, and living in harmony with nature. Unfortunately, in many cases, the amount of things and opportunities that the influencer profession offers can cause frustration in other people because of the inability to fulfill the desires that are created by observing famous people. Very often people are not able to understand that an influencer is only a profession where the current image has nothing to do with reality.

By creating a space for influencers, social media gives them the opportunity to cooperate with brands or approval to create their own products. Marketing created in virtual reality makes it possible to create needs among recipients or to find customers who are already able to buy immediately. Influencer stimulates consumption by awakening in its observers or readers an immediate desire to have a given thing. Very often, an influencer has the power to influence as a leader among a given group, which prompts others to follow their style without reflection on various levels of human activity or to repeat the opinions they create. 


\section{Benefits and threats resulting from the use of mobile devices}

The largest social media supported on mobile devices is visited and used by users tirelessly, with monthly user numbers exceeding billions. Social media using mobile technologies make it possible to create and exchange all user-generated content, but their design is done in such a way as to make society more and more addictive.

Mobile technology, and thus social media, is undoubtedly one of the most important elements of the life of social reality, which makes users systematically check the activities of other users on all social networks, as well as share their own entries, photos, videos or reports. This form of information transmission is very popular, and the majority of the society has profiles on popular websites.

The phenomenon of technological mobility in the context of social reality offers a number of opportunities, but is also a source of new threats. The basic advantages of mobile devices include:

- constant and quick access to the desired information,

- direct exchange of information,

- conducting transactions and interactions in real time, no matter where,

- adjusting the content to the user based on the history of viewed websites, channels, portals, places visited in the past, interests based on likes and observations or installed applications,

- the ability to access your own location in order to determine the whereabouts of the user, e.g. to use a transport service or find a destination,

- introducing innovations in various fields of economic activity,

- organization of everyday time thanks to built-in tools,

- communication speed and being online,

- the ability to express yourself,

- access to entertainment and culture,

- the ability to communicate with people on the other side of the globe.

The incredible development of mobile technologies results from the enormous importance of the Internet and the increase in computing power in transistors, which affects the increasing miniaturization of electronic devices and devices, which in the future may be literally everywhere. Therefore, despite the huge popularity of the technology, its disadvantages should not be forgotten:

- paradoxically, despite the many amounts of security, wireless networks that characterize mobile devices are susceptible to attacks,

- the rapid development of technology leads to a reduction in the security of transactions in the mobile space, shared data and login places,

- mobile devices define identity, interests and situations. 
More and more often you can observe the ternd of leaving information about yourself about spending free time, who the person meets and where, what likes to eat, what music likes to listen to, what to watch, where travels, what currently does, where works, what is his education, what has car, what status, etc. This way he transfers his private life to virtual space. The enormous amount of information about a given user can be used by other users or companies that wish to attract new customers. The use of social networking sites by enterprises offers a great opportunity to create new audiences and the ability to display ads only to users who are likely to be interested in them. Unfortunately, very often such profiling of the Internet user may have negative consequences for him in the future.

\section{Summary}

Mobile technology and social media play a significant role in people's lives. People using mobile devices make all transactions with these devices, and moreover, they discover themselves through their activity, which in turn opens up new opportunities for companies, but becomes dangerous for users. The Internet is the largest source of knowledge, contacts and currently the cheapest communication tool, and the length of spending time on the Internet is constantly increasing.

All kinds of social media based on technological foundations are changing the way entire organizations, societies and individual individuals communicate and undoubtedly become a direct place of information exchange. However, it is important to find the boundary in order to navigate the virtual world properly so as to avoid losing or compromising your own personal data.

\section{References}

1. Czubkowska, S. (2020). Kup 100 fanów na Facebooku - w sieci kwitnie handel ludźmi. Dziennik Gazeta Prawna, 22.07.20, http://www.gazetaprawna.pl/.

2. Gajek, E. (2013). Technologie mobilne w edukacji językowej na przykładzie języka angielskiego. Mazowiecki Kwartalnik Edukacyjny, tom 4, 27-33.

3. Kaplan, A.M., Haenlein, M. (2010) Users of the world, unite! The challenges and opportunities of social media. Business Horizons, No. 53.

4. Krzysztofek, K. (2006). Społeczeństwo w dobie Internetu: refleksyjne czy algorytmiczne? In: Ł. Jonak (ed.), Internet - społeczne aspekty medium: polskie konteksty i interpretacje. Warszawa: Wydawnictwo Akademickie i Profesjonalne. 
5. Kuzior, A., Kochmańska, A., Marszałek-Kotzur, I. (2021). Information and communication technologies as a tool of modern communication in organizations and society. In: K.S. Soliman (ed.), Innovation management and information technology impact on global economy in the era of pandemic. Proceedings of the 37th International Business Information Management Association Conference (IBIMA), 30-31 May 2021, Cordoba, Spain. [B.m.]: International Business Information Management Association, pp. 52405247.

6. Kuzior, A., Sobotka B. (2021). New ICT solutions in public administration. In: K.S. Soliman (ed.), Innovation management and information technology impact on global economy in the era of pandemic. Proceedings of the 37th International Business Information Management Association Conference (IBIMA), 30-31 May 2021, Cordoba, Spain. [B.m.]: International Business Information Management Association, pp. 67436750.

7. Lin, C.A. (2009). Effects of the internet. In: J. Bryant, B. Oliver (eds.), Media Effects. Advances in Theory and Research. New York-London: Routledge.

8. Lysik, Ł., Machura, P. (2014). Rola i znaczenie technologii mobilnych. Media i Społeczeństwo, $n r 4$.

9. Moroz, M. (2010). Źródła efektywności przekazu marketingowego w serwisach społecznościowych. E-mentor, $n r$ 4(36).

10. Naismith, L. et al. (2004). Literature review in mobile technologies and learning. W NESTA Futurelab Literature Review Series, Report 11, 17.07.2020, http://www2.futurelab.org.uk/ resources/documents/lit_reviews/Mobile_Review.pdf.

11. Pawełoszek-Korek, I. (2009). Technologie mobilne $w$ dostarczaniu wiedzy. Częstochowa: Wydawnictwo Politechniki Częstochowskiej.

12. Polańska, K. (2011). Biznesowy charakter mediów społecznościowych. Zeszyty Naukowe Uniwersytetu Szczecińskiego, nr 656.

13. Turban, E., Lee, J., King, D., Warkentin, M., Chung, H. (2002). Electronic Commerce a Managerial Perspective. New Jersey.

14. Wielki, J. (2012). Modele wpływu przestrzeni elektronicznej na organizacje gospodarcze. Wrocław: Wydawnictwo Uniwersytetu Ekonomicznego. 